\title{
Deletion 22 Syndrome with Wide Spectrum of Anomalies: A Case Report
}

\author{
Razieh Sangsari, ${ }^{1,2,}$ and Maliheh Kadivar ${ }^{1,2}$ \\ ${ }^{1}$ Department of Pediatrics, Tehran University of Medical Sciences, Tehran, IR Iran \\ ${ }^{2}$ Division of Neonatology, Children's Medical Center, Pediatrics Center of Excellence, Tehran, IR Iran \\ "Corresponding author: Razieh Sangsari, Children's Medical Center, 62 Gharib St., 1419733151 Tehran, IR Iran. Tel: +98-2166920983, E-mail: raz3532@yahoo.com
}

Received 2016 May 01; Revised 2016 September 25; Accepted 2016 December 20.

Keywords: Delayed Diagnosis, Chromosome, Phenotype, DiGeorge Syndrome

\section{Dear Editor}

DiGeorge syndrome is a congenital disease with a wide spectrum of clinical manifestations including characteristic facial anomalies, congenital heart disease, hypoplastic thymus, immune deficiency, palatal and kidney anomalies, hypocalcemia, and speech and learning disabilities (1). It is associated with submicroscopic deletions of chromosome 22 (22q11.2) (1). Characteristic facial features of this syndrome include periorbital fullness, upslanted and narrow palpebral fissures, prominent nose with large tip and hypoplastic nares, small mouth with everted upper lip and small dysmorphic ears. Some patients, especially in neonatal period, may lack characteristic facial features or show only a subtle facial phenotype (2).

Here, we present a neonate with del 22 syndrome clinically with no distinctive facial features but characteristic finding of del22 in karyotype.

This 31-day-old female infant was referred to our NICU in June 2014 for cardiac care.

She was born at 37 weeks of gestation by vaginal delivery from 25 years old, gravida 1, para 1 mother. Birth weight was 1930 grams, with head circumference of $32 \mathrm{~cm}$ and height of $46 \mathrm{~cm}$. Apgar score was 3 and 5 at 1st and 5th minute, respectively. The mother had no abortion and no remarkable past medical history. The parents had normal appearance with no malformations. Efforts failed to intubate the neonate for resuscitation at the hospital where she was born. Another intubation trial was made with the smallest tracheal tube. Bronchoscopy revealed a subglottic stenosis, which could be dilated. In physical examination, the neonate had normal face, cardiac murmur, and imperforate anus with rectovestibular fistula. Dilatation of fistula allowed full defecation. Because of cardiac disease, surgical repair of the anal anomaly was not possible. Echocardiography showed ventricular septal defect, atrial septal defect, and pulmonary atresia. Ultrasonography of brain and kidneys was normal. Eye examination was also normal. Serologic tests for TORCH and HIV were negative. Other paraclinical findings including $\mathrm{CBC}$, immunology tests, and blood chemistry were normal as well. In OMIM, we found similar reported cases of del22 syndrome

In short, this was a neonate with subglottic stenosis, imperforate anus, and congenital heart defects. She had no facial and palatal anomalies, hypoplastic thymus visible in chest x-ray, or hypocalcemia. Fluorescence in situ hybridization (FISH) revealed deletion in 22q11 region.

Unfortunately, the parents refused a chromosomal analysis; thus, we could not say whether submicroscopic deletions existed or the anomaly was due to a de novo deletion. The patient died due to cardiac disease at the age of 6 months.

Large-scale clinical studies and numerous case reports have shown that DiGeorge syndrome occurs more frequently than previously accepted (1). Digilio et al. described the main clinical features of del22 syndrome with their occurrence in 165 patients and reported that facial anomalies were seen in $100 \%$ of the patients (2). They added that some rare manifestations such as skeletal anomalies of hands and vertebrae, clubfoot, gastrointestinal involvement including intestinal malrotation, tracheoesophageal fistula, esophageal atresia and Hirschsprung's disease can be seen (2). Shprintzen after 30 years of study of the anomaly wrote that del22 syndrome has a wide spectrum of phenotypes with more than 180 clinical manifestations that involve essentially every organ (3), and also found that different dysmorphic features can be seen in different racial groups and different ages (4) and even in one and the same family $(2,4)$. In this way, the spectrum of associated involvements becomes wider (5). According to Marino et al., cardiovascular malformations are always present in these patients (6). Patients without cardiac involvement are at risk of diagnostic delay (7).

This case and similar cases denote the wide clinical manifestations of del22 syndrome. Many patients, espe- 
cially in neonatal period, may have subtle facial features, so that being aware of clinical findings in del22 syndrome in the infants with congenital heart defect, palatal anomalies, hypocalcemia due to hypoparathyroidism and/or hypoplastic thymus in chest $\mathrm{x}$-ray, can help avoid diagnostic delay (Figure 1).

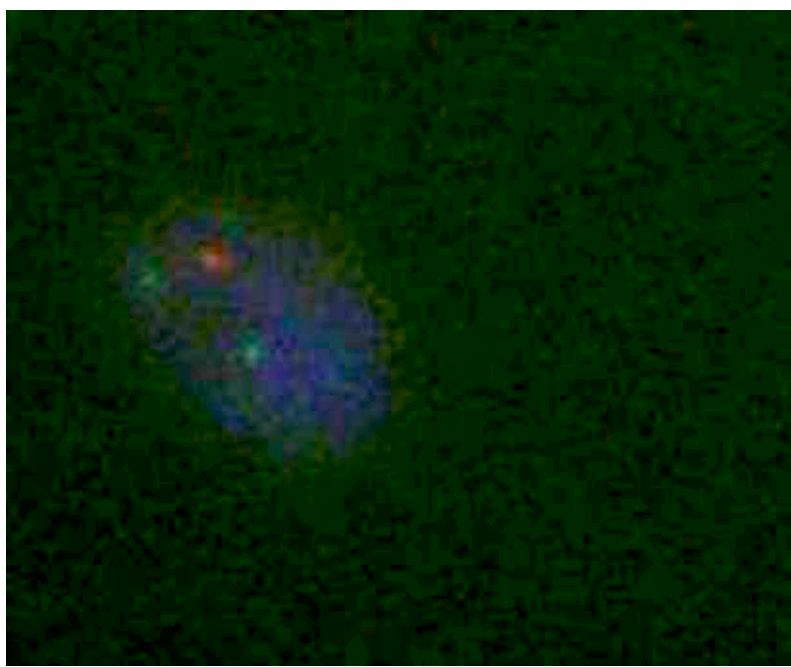

Figure 1. Fluorescence in Situ Hybridization

\section{References}

1. Driscoll DA, Budarf ML, Emanuel BS. Antenatal diagnosis of DiGeorge syndrome. Lancet. 1991;338(8779):1390-1. [PubMed:1682750].

2. Digilio M, Marino B, Capolino R, Dallapiccola B. Clinical manifestations of Deletion 22q11.2 syndrome (DiGeorge/Velo-Cardio-Facial syndrome). Images Paediatr Cardiol. 2005;7(2):23-34. [PubMed: 22368650].

3. Shprintzen RJ. Velo-cardio-facial syndrome: 30 Years of study. Dev Disabil Res Rev. 2008;14(1):3-10. doi: 10.1002/ddrr.2. [PubMed: 18636631].

4. McDonald-McGinn DM, Sullivan KE. Chromosome 22q11.2 deletion syndrome(DiGeorge syndrome/velocardiofacial syndrome). Medicine (Baltimore). 2011;90(1):1-18. doi: 10.1097/MD.0b013e3182060469. [PubMed: 21200182].

5. Digilio MC, Angioni A, De Santis M, Lombardo A, Giannotti A, Dallapiccola B, et al. Spectrum of clinical variability in familial deletion 22q11.2: from full manifestation to extremely mild clinical anomalies. Clin Genet. 2003;63(4):308-13. [PubMed: 12702165].

6. Marino B, Digilio MC, Toscano A, Anaclerio S, Giannotti A, Feltri C, et al. Anatomic patterns of conotruncal defects associated with deletion 22q11. Genet Med. 2001;3(1):45-8. [PubMed: 11339377].

7. Oskarsdottir S, Persson C, Eriksson BO, Fasth A. Presenting phenotype in 100 children with the 22q11 deletion syndrome. Eur $J$ Pediatr. 2005;164(3):146-53. doi: 10.1007/s00431-004-1577-8. [PubMed: 15565286]. 